\title{
Instantaneous center of rotation behavior of the lumbar spine with ligament failure
}

\author{
Laboratory investigation
}

\author{
Yunus Alapan, B.Sc., ${ }^{1}$ Cihan Demir, Ph.D., ${ }^{1}$ Tuncay Kaner, M.D., ${ }^{2}$ Rahmi Guclu, Ph.D., ${ }^{1}$ \\ and Serkan İnCeoĞLu, Ph.D. ${ }^{3}$ \\ ${ }^{1}$ Department of Mechanical Engineering, Yildiz Technical University, Istanbul; ${ }^{2}$ Department of \\ Neurosurgery, School of Medicine, Istanbul Medeniyet University, Istanbul, Turkey; and ${ }^{3}$ Department of \\ Orthopedic Surgery, Loma Linda University, Loma Linda, California
}

\begin{abstract}
Object. The goal of this study was to investigate the effect of ligament failure on the instantaneous center of rotation (ICR) in the lower lumbar spine.

Methods. A 3D finite element model of the L4-5 segment was obtained and validated. Ligament failure was simulated by reducing ligaments in a stepwise manner from posterior to anterior. A pure bending moment of $7.5 \mathrm{Nm}$ was applied to the model in 3 anatomical planes for the purpose of validation, and a 6-Nm moment was applied to analyze the effect of ligament failure. For each loading case, ligament reduction step, and load increment, the range of motion of the segment and the ICR of the mobile (L-4) vertebra were calculated and characterized.

Results. The present model showed a consistent increase in the range of motion as the ligaments were removed, which was in agreement with the literature reporting the kinematics of the L4-5 segment. The shift in the location of the ICR was below $5 \mathrm{~mm}$ in the sagittal plane and $3 \mathrm{~mm}$ in both the axial and coronal planes.

Conclusions. The location of the ICR changed in all planes of motion with the simulation of multiple ligament injury. The removal of the ligaments also changed the load sharing within the motion segment. The change in the center of rotation of the spine together with the change in the range of motion could have a diagnostic value, revealing more detailed information on the type of injury, the state of the ligaments, and load transfer and sharing characteristics of the segment.

(http://thejns.org/doi/abs/10.3171/2013.3.SPINE12923)
\end{abstract}

\section{KEY Words - lumbar spine • ligament failure • finite element • instantaneous center of rotation}

$\mathrm{P}$ ROPER motion of the spine is orchestrated by the coordination of both active (muscles) and passive (disc, facets, and ligaments) structures. Muscle failure in the spine would typically only hinder the body's ability to move normally in day-to-day living. However, since a major function of spinal ligaments is to provide stability to the spine by allowing a balanced and restrained motion during the activities of daily living, ${ }^{43} \mathrm{a}$ failure in the functions of these passive structures may place the spine at serious risk for injury.

\footnotetext{
Abbreviations used in this paper: ALL = anterior longitudinal ligament; $\mathrm{CL}=$ capsular ligament; $\mathrm{FE}$ = finite element; $\mathrm{ICR}=$ instantaneous center of rotation; ISL $=$ interspinous ligament; ITL = intertransverse ligament; $\mathrm{LF}=$ ligamentum flavum; $\mathrm{PLL}=$ posterior longitudinal ligament; SSL = supraspinous ligament.
}

The individual contributions of spinal ligaments have been investigated in several studies.,12,15,24,28,30 By sequentially cutting the ligaments, researchers have analyzed the changes in the range of motion of the spinal segments to assess the role of each ligament in spine kinematics. The changes in the segmental stiffness and range of motion of the spine specimens have been documented in biomechanical evaluations in which either traditional flexibility testing, ${ }^{15,24,28,30}$ hybrid testing protocols, ${ }^{2}$ or robotic applications were used. ${ }^{12}$

Although it has been shown in several biomechanical studies that ligament failure is associated with increased range of motion and the loss of segmental stiff-

This article contains some figures that are displayed in color online but in black-and-white in the print edition. 
ness, $2,12,15,24,28,30$ there is no information on the change in the quality of the motion as assessed and defined by the ICR, which is a point on the axis of rotation found at a planar section of the motion segment. Understanding the quality of spinal motion as well as the quantity can assist in the diagnosis of ligamentous injury and the determination of the optimal treatment strategy. Therefore, the aim of the current study was to assess the changes in the location of the ICR caused by various ligament failures, loading levels, and loading directions.

\section{Methods}

For this study, an FE model of a human L4-5 segment was obtained from open-access CT images (Visible Human Project of the United States National Library of Medicine $^{42}$ ). A 3D solid model was obtained using ImageVis3D (Scientific Computing and Imaging Institute) and CATIA (Dassault Systems). After FE modeling with ANSA software (BETA CAE Systems SA) the model was imported into ANSYS version 13.0 (Swanson Analysis) for FE analysis (Fig. 1).

The vertebrae were modeled with a cortical shell (with 0.5-mm-thick wedge elements ${ }^{13}$ ) and trabecular core (with tetrahedral and pyramid elements). Spinal ligaments were modeled with tension-only spring elements. The FE model consisted of 1230 link, 300 spring, and 270,324 solid elements.

The annulus ground substance and nucleus pulposus were modeled using hexahedral elements. The collagen fibers embedded in the annulus layers were modeled using tension-only link elements. The ratio of fiber volume to the surrounding ground substance volume changed from $5 \%$ to $23 \%$ from the inner to outer layers. ${ }^{22}$

Facet cartilage layers were modeled using hexahedral elements. The facet joint was assumed to have a frictionless contact. The contact stiffness was assumed to be 200 $\mathrm{N} / \mathrm{mm},{ }^{37}$ and the initial gap between the cartilage layers was defined as $0.5 \mathrm{~mm} .^{32}$

The details of the material properties of the cortical and trabecular bone, posterior bony elements, facet cartilage layers, annulus fibers, cartilage endplate, $, 9,13,20,31,36,47$ annulus ground substance, nucleus pulposus, ${ }^{14,36}$ and ligaments ${ }^{25,27,33,36,47}$ were based on the literature (Table 1).

\section{Models With Ligament Failure}

Ligament failures were simulated by the sequential reduction of the 7 ligaments in the following order: SSL, ISL, LF, CL, ITL, PLL, and ALL.

\section{Load and Boundary Conditions}

The nodes on the inferior surface of L-5 were constrained in all directions. The L-4 vertebra was free to move in all directions. The loading was applied to the L-4 superior endplate via (virtual) rigid beam elements, where the load was applied to a single node on one end, and distributed homogeneously to the nodes of the superior endplate on the opposite end. For the validation analysis a $7.5-\mathrm{Nm}$ bending moment was applied to the intact spine model, which was the choice of loading in the previous studies with which the current results were compared. However, a bending moment of $6 \mathrm{Nm}$ was applied to the injured spine model in all planes of motion. Large deformations and elastic material properties were considered in the analysis.

\section{Data Analysis}

The ICR was determined using the intersection of the perpendicular bisectors of displacement vectors of 2 peripheral nodes of the inferior endplate of the L-4 verte-
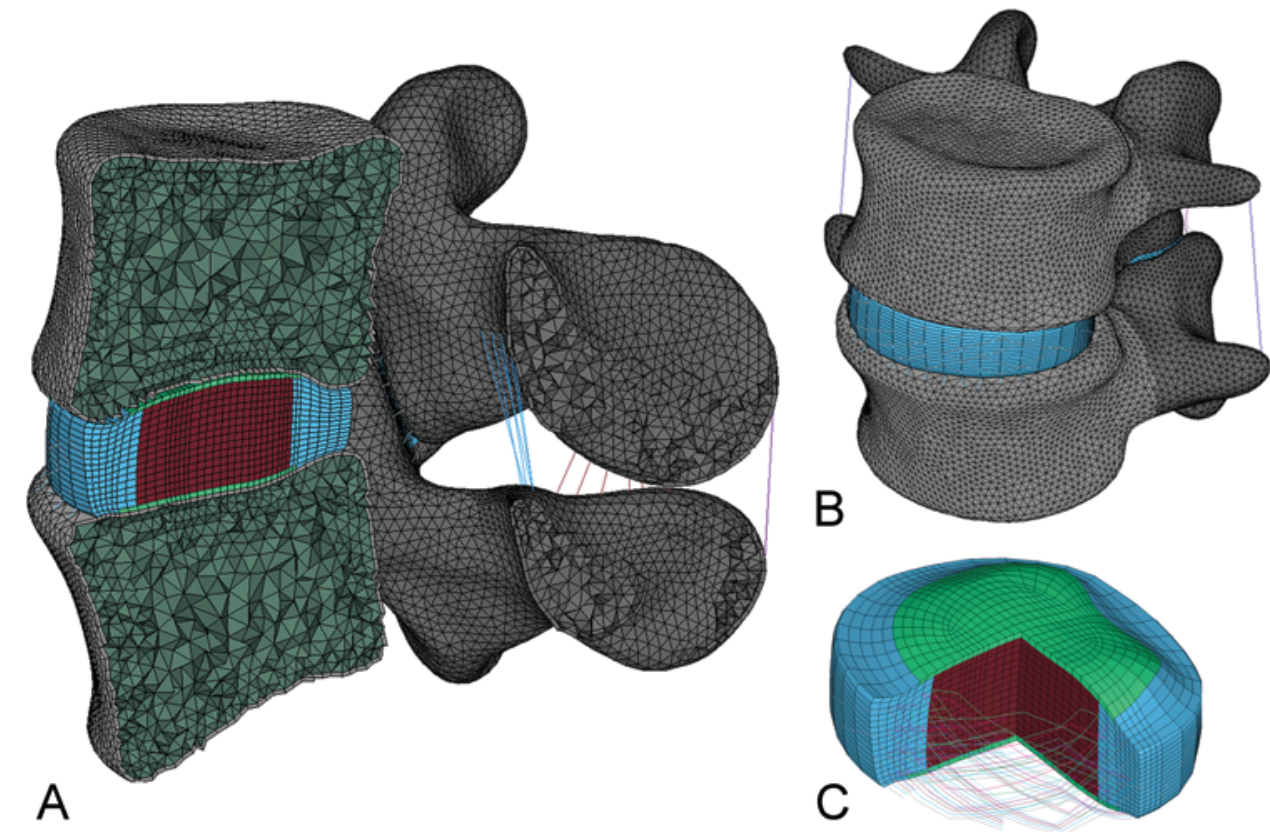

Fig. 1. Section view of the FE model of the segment (A), whole view of the model $(B)$, and intervertebral disc structure with annulus fibers $(\mathbf{C})$. 
Change of ICR with ligament failure

TABLE 1: Material properties used in the FE model*

\begin{tabular}{|c|c|c|c|c|}
\hline Structure & Young Modulus (MPa) & Poisson Ratio & Cross-Section $\left(\mathrm{mm}^{2}\right)$ & Mooney-Rivlin \\
\hline \multicolumn{5}{|l|}{ vertebra } \\
\hline cortical bone & 5000 & 0.3 & NA & \\
\hline cancellous bone & 50 & 0.2 & NA & \\
\hline posterior elements & 3000 & 0.3 & NA & \\
\hline facet cartilage layers & 10.4 & 0.4 & & \\
\hline intervertebral disc & & & NA & \\
\hline nucleus pulposus & & & & $C_{1}=0.017, C_{2}=0.004$ \\
\hline annulus fibers & 175 & 0.3 & $0.1-0.78$ & \\
\hline annulus ground substance & & & & $C_{1}=0.18, C_{2}=0.045$ \\
\hline cartilage endplate & 23.8 & 0.4 & NA & \\
\hline ligament† & & & & \\
\hline
\end{tabular}

bra. ${ }^{29,35}$ The ICR of the motion segment was investigated for all subsequent ligament failure conditions, 4 motion directions (flexion, extension, right lateral bending, and clockwise axial rotation), and 4 levels of loading (1.5, 3, 4.5 , and $6 \mathrm{Nm}$ ). For the sake of brevity the left lateral bending and counterclockwise rotation were ignored due to their symmetry, similar to other studies..$^{35,37,41,45}$ The change in the characteristics of the centrode, that is, the path that the ICR followed during a full loading cycle, was calculated. ${ }^{5}$ The length of the centrode was defined as the length of the path that the ICR followed during the loading cycle, the translation of the ICR was defined as the distance between the start and end points of the centrode during loading, and the displacement of the centrode was defined as the difference between the center of the current centrode and that of the intact centrode. The length of the centrode was similar to the translation of the ICR when the centrode was linear, but they differed when the centrode was curvy.

Facet joint forces for each facet (left and right), in sagittal motion, were calculated one by one as a vector summation of the 3 force components (x, y, and $\mathrm{z}$ directions) and averaged. Annulus stresses were defined as the maximum von Mises stress on the annulus in sagittal motion.

\section{Results}

\section{Range of Motion and Stress Analysis}

Range of Motion Analysis for the Intact Model. The present intact model was validated by comparing our results with those from in vitro and FE studies performed under similar boundary and loading conditions ${ }^{16,18,19,34,38,48}$ (Fig. 2). The current FE model successfully estimated the previously published range of motion data for the L4-5 segment.

Range of Motion Analysis for Models With Ligament Failure. For flexion, failure of the SSL caused a slight increase in range of motion, but the ISL was found to have a substantial effect on the range of motion (Fig. 3). Also, the removal of the LF and ITL had similar effects on the range of motion, but lower than that of the ISL. The CL had the most significant effect on the range of motion in flexion. Furthermore, the failure of the PLL caused a slight increase and, as anticipated, the ALL had no effect on the range of motion in flexion. In the case of extension, only the removal of the ALL caused an increase in the range of motion. For lateral bending, the ITL had the most significant effect on range of motion. Besides the ITL, the CL and ALL had a considerable effect on range of motion in lateral bending. In axial rotation, the CL, PLL, and ALL caused a slight increase in range of motion.

Facet Loads and Annulus Stresses. Facet loads increased in extension by approximately $10 \%$ and $60 \%$ with respect to the intact condition with the removal of the $\mathrm{CL}$ and ALL, respectively (Table 2). There were no facet forces in flexion. In flexion, annulus stress increased with the removal of the posterior ligaments, especially with the removal of the CL. In extension, the maximum increase in annulus stress due to the ligament removal was approximately $15 \%$ with respect to the intact condition, which occurred after the ALL removal. Maximum annulus stress was found to occur on the anteroinferior rim of the annulus for all ligament failure scenarios in flexion, and there was a gradual increase in stress on the posteroinferior edge with the subsequent ligament removal. In extension, maximum annulus stress was found to occur on the anteroinferior edge for all conditions except the ALL removal. There was a slight lateral move in the location of the maximum annulus stress area with the transection of the ALL as well as a slight decrease in stress at the posteroinferior annulus.

\section{Analysis of the ICR}

The ICR Versus Motion Directions in Intact Segment. In the sagittal motion, the ICR was found to be closer to the superior endplate of the L-5 vertebral body (Figs. 4 and 


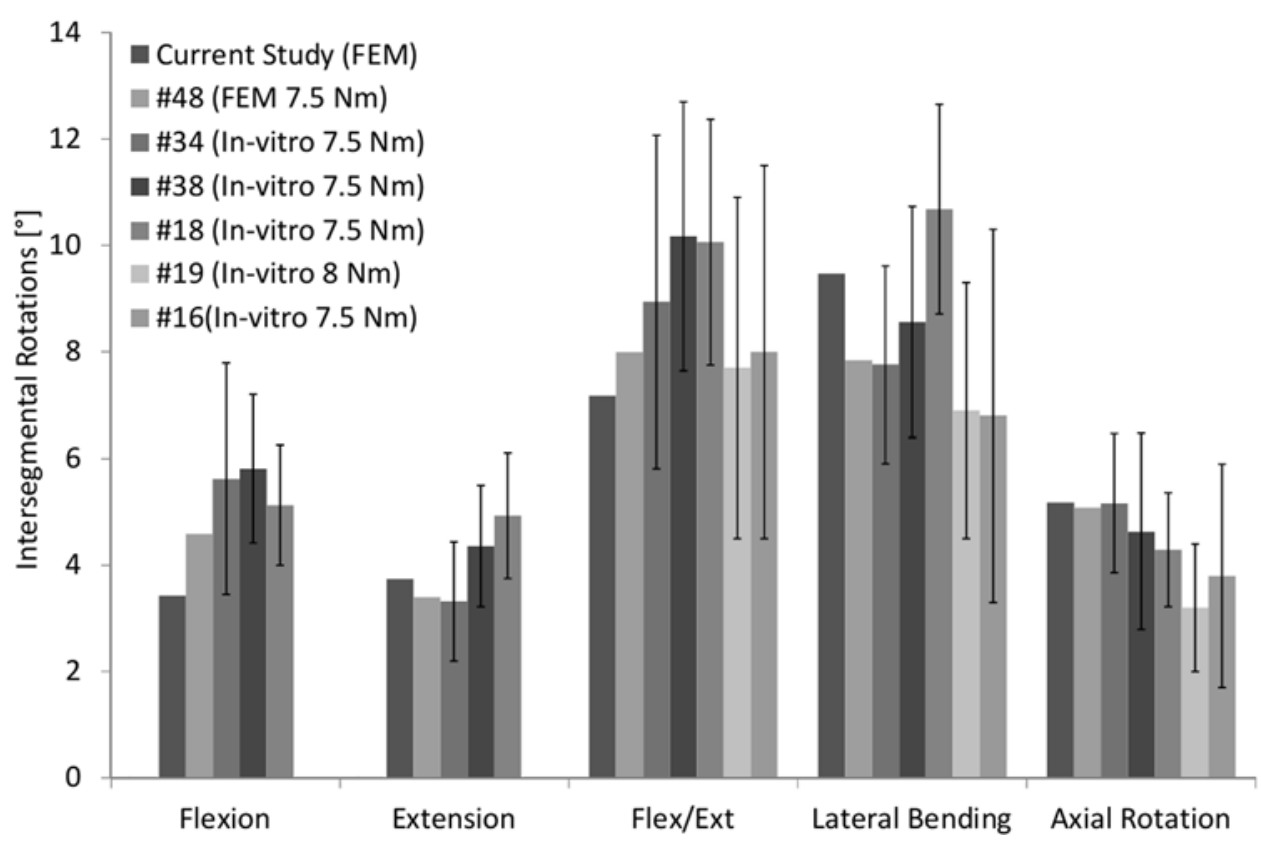

Fig. 2. Bar graph showing the validation of the intersegmental range of motion results of the current study (obtained with 7.5-Nm bending moment) compared with results of the computational and in vitro studies from the literature. The \# symbols and numbers denote the reference number of the study. FEM $=$ FE model; Flex/Ext $=$ flexion/extension.

5). The length of the centrode and the total displacement of the ICR were larger in flexion than extension (Table 3). In the lateral bending, the ICR was in the disc space, close to the center (Fig. 6). In axial rotation, the ICR was around the posterolateral aspect of the L-5 vertebral body (Fig. 7). During axial rotation, the length of the centrode along with the total translation of the ICR increased markedly compared with those in the sagittal and lateral motion.

The ICR Versus Ligament Failure in Injured Segment. In flexion the centrode of the ICRs was mainly located at the superior endplate and posterior one-third of the L-5 vertebra in the intact model. It shifted anteriorly and superiorly by $0.01 \mathrm{~mm}$ after removal of the SSL, and by 4.31 $\mathrm{mm}$ after subsequent removal of the ISL, LF, ITL, CL, and PLL. The centrode became shorter as the ligaments were removed. In extension the centrode was initially located in the middle third of the superior L-5 endplate, and shifted $4.11 \mathrm{~mm}$ posteriorly and superiorly when all the ligaments were reduced. The length of the centrode substantially increased after the reduction of the ALL. In lateral bending

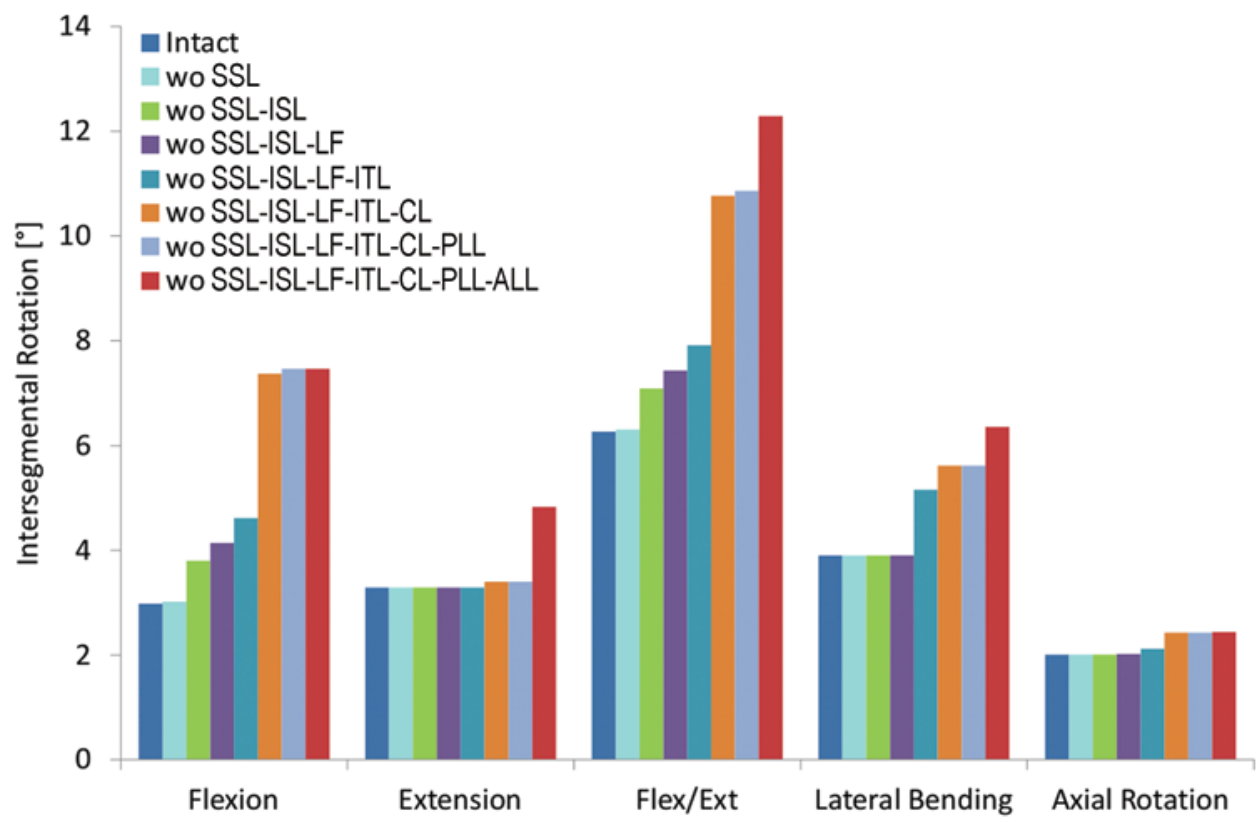

FIG. 3. Bar graph showing intersegmental range of motion results under 6-Nm bending moments for different ligament failure conditions and loading directions. wo = without. 


\section{Change of ICR with ligament failure}

TABLE 2: The average facet forces and maximum annulus stresses in the sagittal plane for subsequent ligament removal* $^{*}$

\begin{tabular}{|c|c|c|c|c|}
\hline \multirow[b]{2}{*}{ Condition } & \multicolumn{2}{|c|}{ Max Annulus Stresses (MPa) } & \multicolumn{2}{|c|}{ Facet Forces $(\mathrm{N})$} \\
\hline & Flexion & Extension & Flexion & Extension \\
\hline intact & 0.58 & 0.71 & NA & 121.38 \\
\hline w/o SSL & 0.59 & 0.71 & NA & 121.38 \\
\hline$w / 0+I S L$ & 0.75 & 0.71 & NA & 121.38 \\
\hline$w / 0+L F$ & 0.82 & 0.71 & NA & 121.38 \\
\hline$w / 0+I T L$ & 0.88 & 0.71 & NA & 121.38 \\
\hline$w / 0+C L$ & 1.46 & 0.73 & NA & 136.27 \\
\hline$w / 0+P L L$ & 1.48 & 0.73 & NA & 136.27 \\
\hline$w / 0+A L L$ & 1.48 & 0.81 & NA & 190.64 \\
\hline
\end{tabular}

* The plus sign means that a ligament removal is in addition to the removal of the previous ligaments. For instance, + ISL means removal of SSL and ISL; + LF means removal of SSL, ISL, and LF; and so on. Abbreviation: max = maximum.

the ICR was initially found at the center of disc; however, it moved laterally by $2.13 \mathrm{~mm}$ with the simulation of full ligament failure. In axial rotation the ICR was located at the posterolateral rim of the vertebral endplate. With the simulation of ligament failures, the length of the centrode increased from 4.15 to $5.10 \mathrm{~mm}$, and the location of the centrode shifted $2.43 \mathrm{~mm}$. In all planes the length of the centrode and total translation of the ICR were similar, indicating a near-linear shape of the centrode.

\section{Discussion}

\section{The ICR and Ligament Failure}

In this study we investigated the behavior of the ICR of the lower lumbar spine for various ligament failure conditions. The results showed that a small shift occurred in the ICR with ligament failure compared with the intact condition. We showed that maximum change in the location of the centrode (that is, the path that the ICR followed during a full loading cycle) due to ligament failure was below $5 \mathrm{~mm}$ in the sagittal plane and $3 \mathrm{~mm}$ in both axial and coronal planes.

Our study showed that in the event of a particular ligament failure, the ICR moved in the direction of the motion, especially in sagittal motion. A shift in the ICR away from the column of instability was also observed, which matches the results of previous experimental studies.,17,26,39 In flexion, the removal of all of the ligaments carried the ICR anteriorly and superiorly, toward the cen-

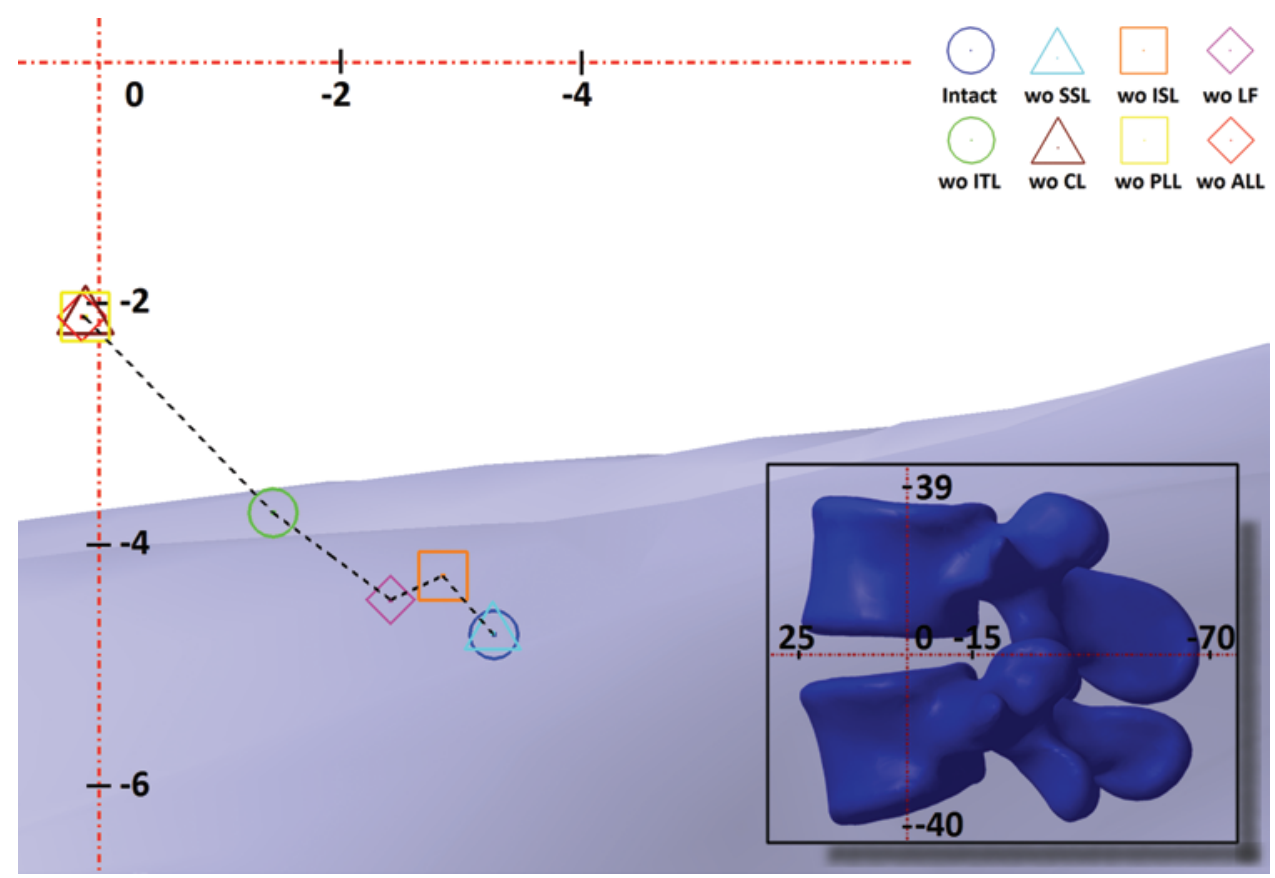

FIG. 4. Chart showing change of mean position of ICR with subsequent ligament transection in flexion. $+=$ values for anterior and superior directions; - = values for posterior and inferior directions. (Values for the coordinate system are in millimeters for Figs. 4-7.) 


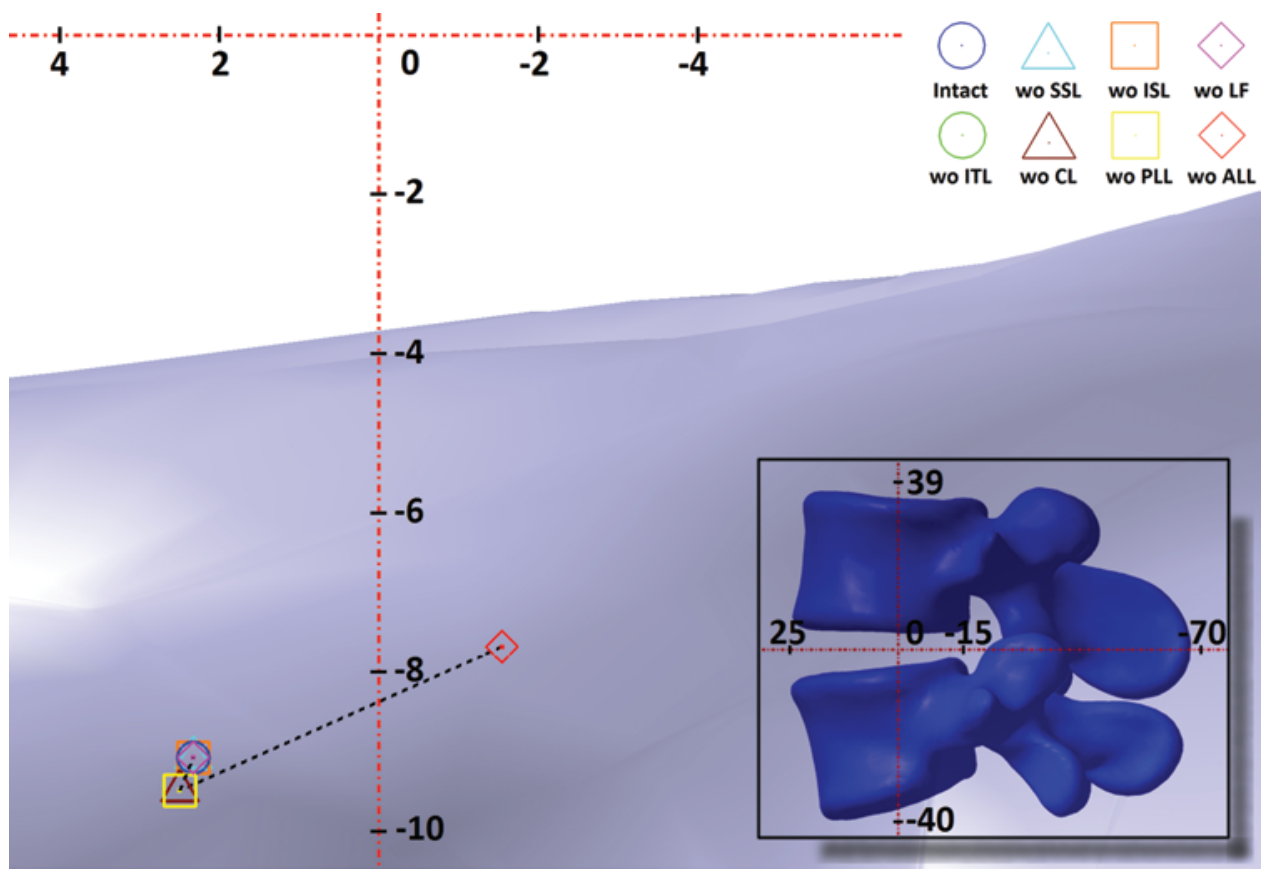

FIG. 5. Chart showing change of mean position of ICR with subsequent ligament transection in extension. $+=$ values for anterior and superior directions; - = values for posterior and inferior directions.

ter of the disc. This result was also in agreement with a previous study, ${ }^{5}$ which stated that the reduced posterior ligament stiffness was a passive factor causing upward and forward displacement of the ICR. In extension, with removal of all of the ligaments, the centrode moved consistently toward the facet joints as the bending moment increased. When all the ligaments were reduced, the resistance of the spine against translation was weakened. This instability resulted in the closure of the facet gaps and increase in facet load sharing. Thus, the shift in the ICR toward facets indicated an abnormality in translation and increased facet loads.

In lateral bending, ligament failure did not cause a significant change in the location of the ICR, mostly because all of the ligaments were either symmetrical or on the neutral axis of right lateral rotation. There was only a slight movement of the ICR to the perimeter of the disc, which indicated that the presence of ligaments helped

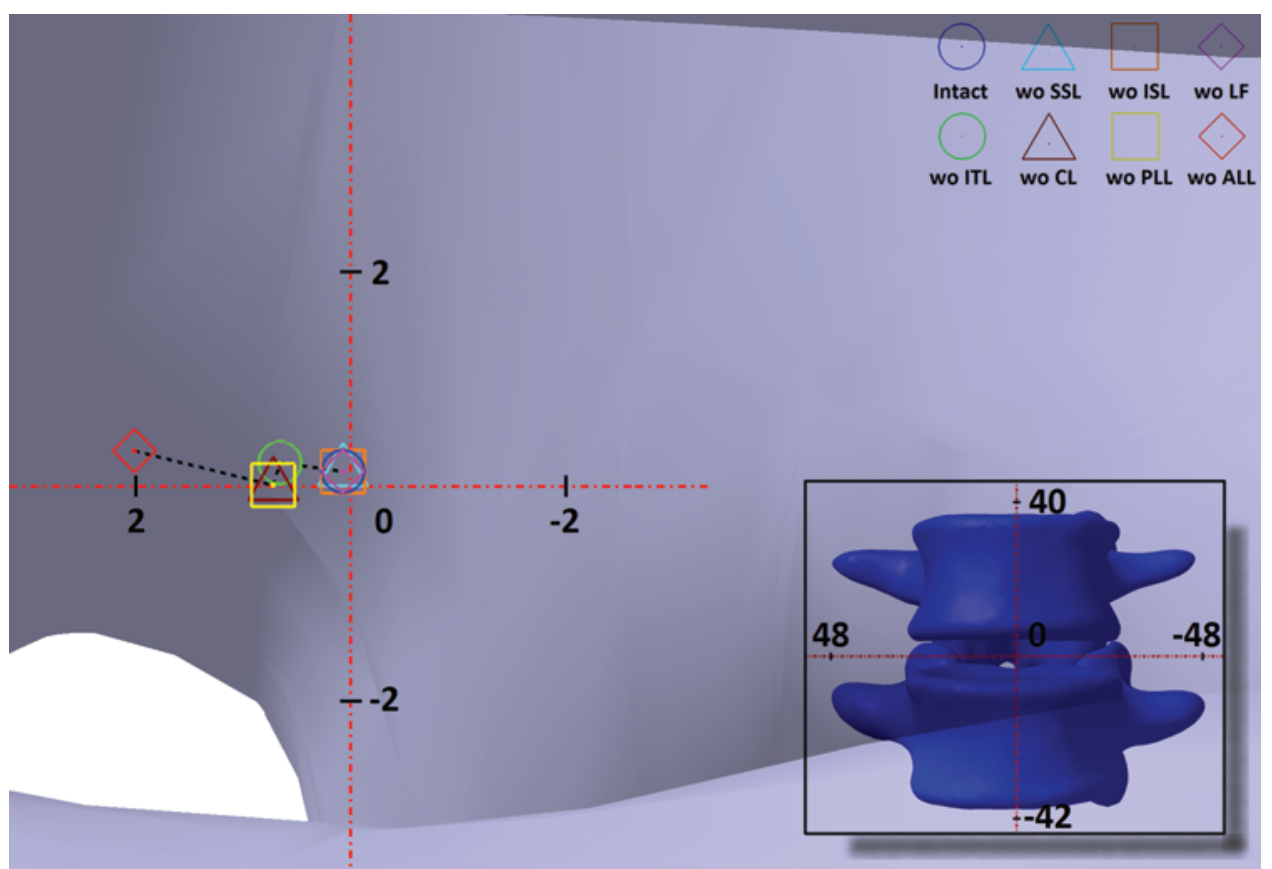

FIG. 6. Chart showing change of mean position of ICR with subsequent ligament transection in right lateral bending. $+=$ values for superior and left lateral directions; - = values for inferior and right lateral directions. 
Change of ICR with ligament failure

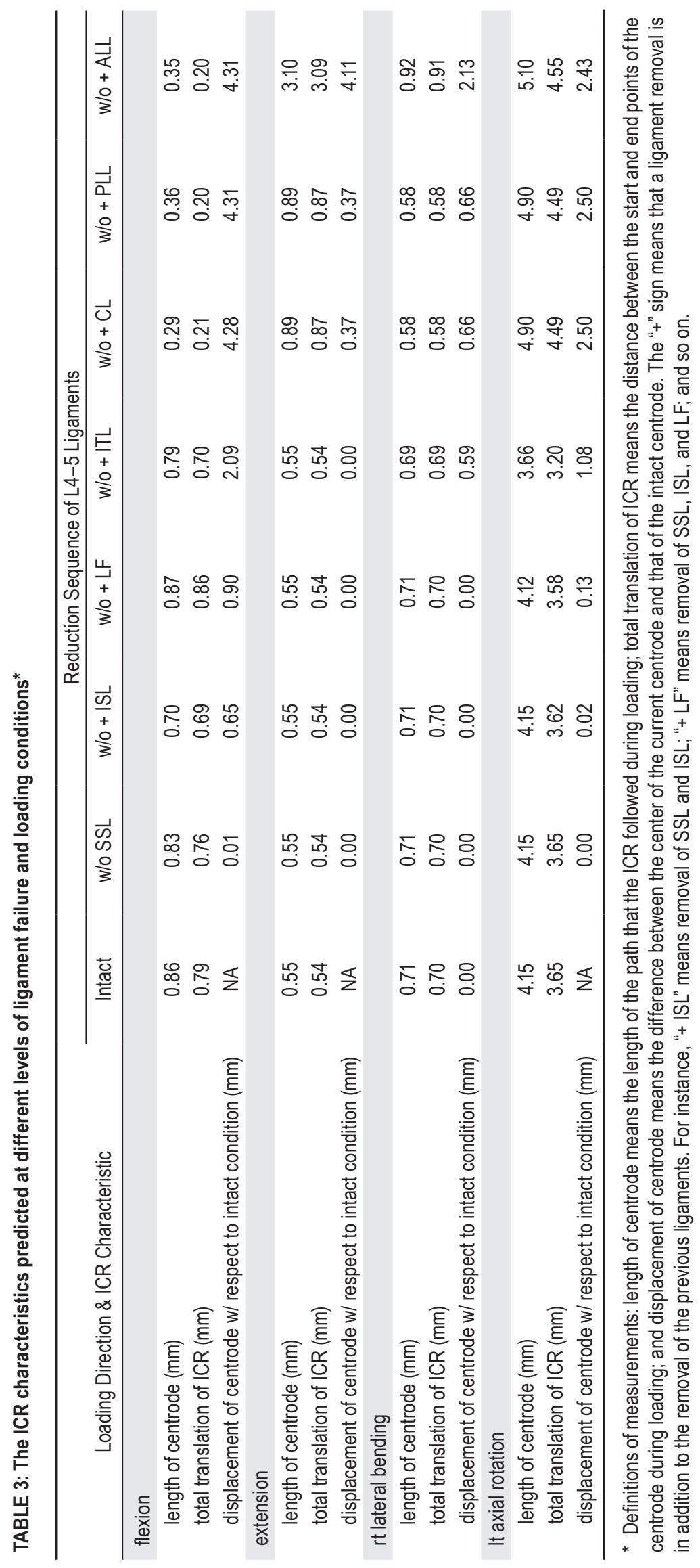




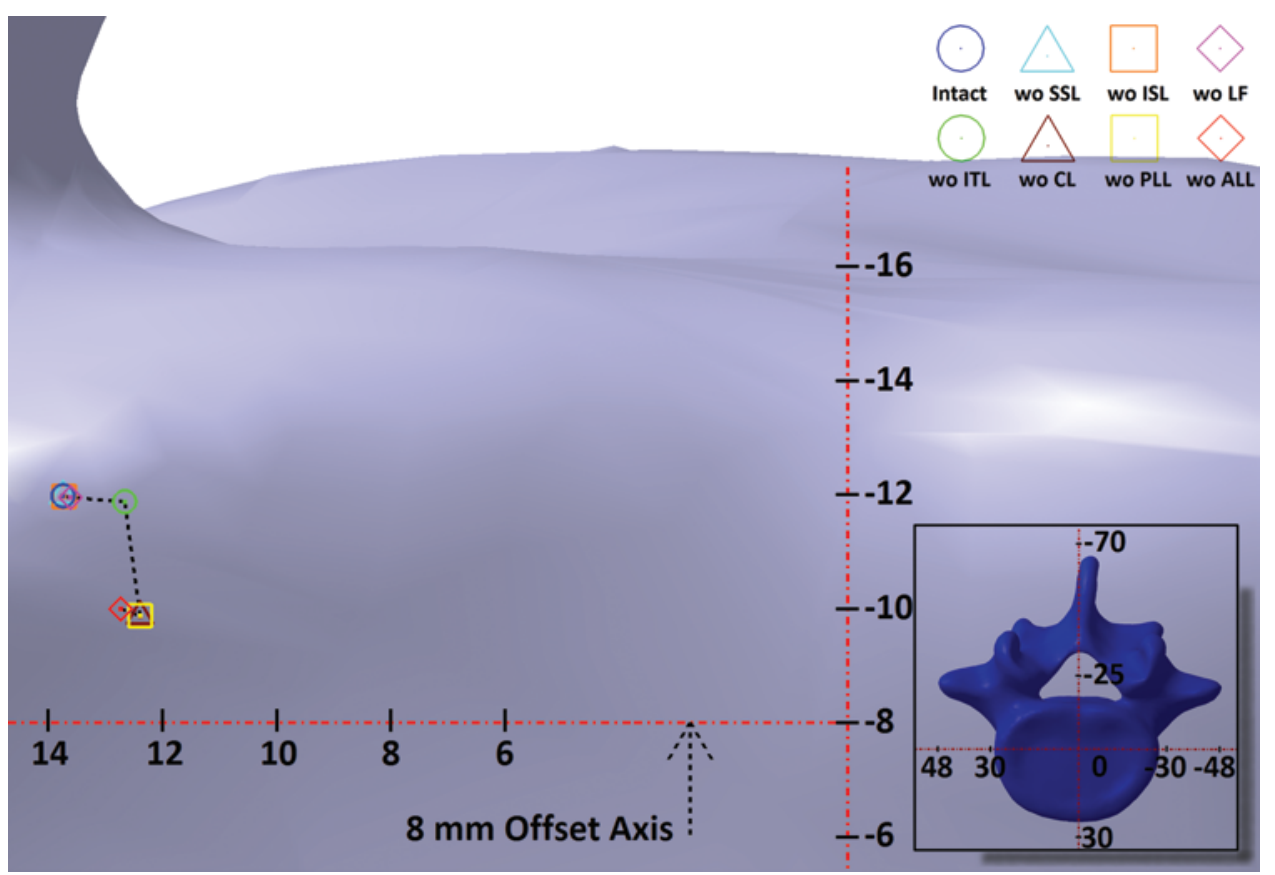

FIG. 7. Chart showing change of mean position of ICR with subsequent ligament transection in left axial rotation. $+=$ values for anterior and left lateral directions; - = values for posterior and right lateral directions.

maintain the balanced kinematics of the spinal unit in the coronal plane. Similar to lateral bending, the ICR in axial rotation neither shifted markedly nor showed a pattern in various ligament failure conditions.

The change of the position of the ICR, and thus the formation of a centrode, is associated with translational motion in the functional spinal unit. ${ }^{40}$ The translational motion of the spinal segment is controlled and limited by the 3-joint complex of the segment, constituted by the intervertebral disc, facet joints, and ligaments. ${ }^{44}$ Thus, any dysfunction in this 3-joint complex can cause abnormality in the translational motion of the segment. In the present study this change in the length of the centrode, and thus the translational motion, was evident in all directions of motion. With the knowledge regarding the relationship of disc degeneration and ICR,${ }^{40,43}$ as well as column deficiency and $\mathrm{ICR}^{7,17,26,39}$ on the one hand and the results of this study on the other, it appears that the ICR can have a diagnostic value in defining the source of segmental instability.

\section{Quantitative Analysis}

Other studies have emphasized the biomechanical importance of the posterior ligaments..$^{1,2,8,21}$ Adams et al. ${ }^{2}$ investigated the contributions of the posterior ligaments to the resistance of the segment in flexion by using a stiffness protocol. They stated that the CL provided more resistance to flexion compared with the ISL/SSL, which is in agreement with the current findings. In contrary, Gillespie and Dickey ${ }^{12}$ found that the ISL/SSL were the major contributors to segmental resistance in flexion by using a parallel linkage robotic protocol in a porcine model. Heuer et al. ${ }^{15}$ attributed this difference to the interspecies differences and the nature of multisegmental testing. In a more recent study, Heuer et al. used a flexibility protocol to study the range of motion and lordosis angle changes with the subsequent removal of spinal structures. Similar to our study, they found a slight increase in the range of motion with the removal of the ISL/SSL, but they did not show any significant role of the CL in flexion. In extension, they also found a slight increase in the range of motion after the removal of the CL and a greater increase with the removal of the ALL, which was similar to our findings.

Clinically, it is known that decompressive lumbar surgery including removal of the lamina deteriorates the interspinous and supraspinous ligaments, the capsular ligament, and facet joints. ${ }^{6,10,11}$ Secondary segmental instability, which is seen after lumbar disc surgery, has been described as "status post discectomy." This kind of instability was referred to by Benzel $^{3}$ as chronic instability, which is an important health problem related to the lumbar spine. In another study, Cusick et al. ${ }^{8}$ showed that reduction of the posterior soft tissue, ligaments, and facet joints increased the stress on the ALL and PLL and on the annulus of the disc tissue.

With subsequent ligament removal, the increase in the annulus stress in flexion was far greater than in extension. This was due to the increasing load share of facets in extension, whereas in flexion the disc was left alone to bear the entire load after the removal of ligaments. This could also be easily seen in the interaction between the range of motion and the annulus stress in flexion. In extension, however, there was a weaker correlation because of the complex load-sharing characteristics between the annulus and facets.

There is a large span of ligament stiffness values available in the literature. It has to be noted that different ligament stiffness selections can yield different quantitative results. ${ }^{46}$ As Panjabi et al. ${ }^{23}$ showed, lengths and points 
of attachments (orientations) of ligaments can change the results significantly. In this study, based on the literature, we assigned the material properties of the ligament that would produce realistic range-of-motion values. The effect of the variability in modeling methods and material properties on the ICR calculation can be investigated in future studies by using probabilistic methods; however, it was not in the scope of the current study. Furthermore, when studying the ligament contributions with a stepwise removal methodology, as Heuer et al..$^{15}$ noted, the order of removal matters. With that being the case, the results of the current study are only valid for the present ligament reduction order.

\section{Conclusions}

The location of the ICR changed in all planes of motion with the simulation of multiple ligament injury. The removal of the ligaments also changed the load sharing within the motion segment. The change in the center of rotation of the spine together with the change in the range of motion could have a diagnostic value, revealing more detailed information on the type of the injury, the state of the ligaments, and the load-transfer and load-sharing characteristics of the segment.

\section{Disclosure}

The authors report no conflict of interest concerning the materials or methods used in this study or the findings specified in this paper.

Author contributions to the study and manuscript preparation include the following. Conception and design: all authors. Acquisition of data: Alapan, Demir. Analysis and interpretation of data: all authors. Drafting the article: İnceoğlu, Alapan, Kaner. Critically revising the article: all authors. Reviewed submitted version of manuscript: all authors. Approved the final version of the manuscript on behalf of all authors: İnceoğlu. Administrative/technical/material support: Demir, Guclu. Study supervision: İnceoğlu.

\section{References}

1. Adams MA, Hutton WC: The mechanical function of the lumbar apophyseal joints. Spine (Phila Pa 1976) 8:327-330, 1983

2. Adams MA, Hutton WC, Stott JR: The resistance to flexion of the lumbar intervertebral joint. Spine (Phila Pa 1976) 5: 245-253, 1980

3. Benzel EC: Biomechanics of Spine Stabilization, ed 2. Rolling Meadows, IL: AANS, 2001

4. Boden SD, Frymoyer JW: Segmental instability: overview and classification, in Frymoyer JW (ed): The Adult Spine: Principles and Practice, ed 2. Philadelphia: Lippincott-Raven Publishers, 1997, pp 2137-2155

5. Bogduk N, Amevo B, Pearcy M: A biological basis for instantaneous centres of rotation of the vertebral column. Proc Inst Mech Eng H 209:177-183, 1995

6. Caputy AJ, Luessenhop AJ: Long-term evaluation of decompressive surgery for degenerative lumbar stenosis. J Neurosurg 77:669-676, 1992

7. Cossette JW, Farfan HF, Robertson GH, Wells RV: The instantaneous center of rotation of the third lumbar intervertebral joint. J Biomech 4:149-153, 1971

8. Cusick JF, Yoganandan N, Pintar FA, Reinartz JM: Biomechanics of sequential posterior lumbar surgical alterations. J Neurosurg 76:805-811, 1992

9. Denozière G, Ku DN: Biomechanical comparison between fu- sion of two vertebrae and implantation of an artificial intervertebral disc. J Biomech 39:766-775, 2006

10. Fager CA, Freidberg SR: Analysis of failures and poor results of lumbar spine surgery. Spine (Phila Pa 1976) 5:87-94, 1980

11. Garfin SR, Glover M, Booth RE, Simeone FA, Rothman RH: Laminectomy: a review of the Pennsylvania hospital experience. J Spinal Disord 1:116-133, 1988

12. Gillespie KA, Dickey JP: Biomechanical role of lumbar spine ligaments in flexion and extension: determination using a parallel linkage robot and a porcine model. Spine (Phila Pa 1976) 29:1208-1216, 2004

13. Goel VK, Grauer JN, Patel TCh, Biyani A, Sairyo K, Vishnubhotla S, et al: Effects of charité artificial disc on the implanted and adjacent spinal segments mechanics using a hybrid testing protocol. Spine (Phila Pa 1976) 30:2755-2764, 2005

14. Goel VK, Kong W, Han JS, Weinstein JN, Gilbertson LG: A combined finite element and optimization investigation of lumbar spine mechanics with and without muscles. Spine (Phila Pa 1976) 18:1531-1541, 1993

15. Heuer F, Schmidt H, Klezl Z, Claes L, Wilke HJ: Stepwise reduction of functional spinal structures increase range of motion and change lordosis angle. J Biomech 40:271-280, 2007

16. Ilharreborde B, Shaw MN, Berglund LJ, Zhao KD, Gay RE, An KN: Biomechanical evaluation of posterior lumbar dynamic stabilization: an in vitro comparison between Universal Clamp and Wallis systems. Eur Spine J 20:289-296, 2011

17. James KS, Wenger KH, Schlegel JD, Dunn HK: Biomechanical evaluation of the stability of thoracolumbar burst fractures. Spine (Phila Pa 1976) 19:1731-1740, 1994

18. Karahalios DG, Kaibara T, Porter RW, Kakarla UK, Reyes PM, Baaj AA, et al: Biomechanics of a lumbar interspinous anchor with anterior lumbar interbody fusion. Laboratory investigation. J Neurosurg Spine 12:372-380, 2010

19. Kotani Y, Cunningham BW, Abumi K, Dmitriev AE, Hu N, Ito $\mathrm{M}$, et al: Multidirectional flexibility analysis of anterior and posterior lumbar artificial disc reconstruction: in vitro human cadaveric spine model. Eur Spine J 15:1511-1520, 2006

20. Kumaresan S, Yoganandan N, Pintar FA: Finite element modeling approaches of human cervical spine facet joint capsule. J Biomech 31:371-376, 1998

21. Lorenz M, Patwardhan A, Vanderby R Jr: Load-bearing characteristics of lumbar facets in normal and surgically altered spinal segments. Spine (Phila Pa 1976) 8:122-130, 1983

22. Lu YM, Hutton WC, Gharpuray VM: Do bending, twisting, and diurnal fluid changes in the disc affect the propensity to prolapse? A viscoelastic finite element model. Spine (Phila Pa 1976) 21:2570-2579, 1996

23. Panjabi MM, Goel VK, Takata K: Physiologic strains in the lumbar spinal ligaments. An in vitro biomechanical study 1981 Volvo Award in Biomechanics. Spine (Phila Pa 1976) 7:192-203, 1982

24. Panjabi MM, White AA III, Johnson RM: Cervical spine mechanics as a function of transection of components. J Biomech 8:327-336, 1975

25. Pingel TH: Beitrag zur Herleitung und numerischen Realisierung eines mathematischen Modells der menschlichen Wirbelsaüle. Castrop-Rauxel, Germany: Thomas Henrich Pingel, 1991

26. Pintar FA, Cusick JF, Yoganandan N, Reinartz J, Mahesh M: The biomechanics of lumbar facetectomy under compressionflexion. Spine (Phila Pa 1976) 17:804-810, 1992

27. Polikeit A, Ferguson SJ, Nolte LP, Orr TE: Factors influencing stresses in the lumbar spine after the insertion of intervertebral cages: finite element analysis. Eur Spine J 12:413-420, 2003

28. Posner I, White AA III, Edwards WT, Hayes WC: A biomechanical analysis of the clinical stability of the lumbar and lumbosacral spine. Spine (Phila Pa 1976) 7:374-389, 1982

29. Reuleaux F: The Kinematics of Machinery: Outline of a Theory of Machines. London: Macmillan, 1876 
30. Richter M, Wilke HJ, Kluger P, Claes L, Puhl W: Load-displacement properties of the normal and injured lower cervical spine in vitro. Eur Spine J 9:104-108, 2000

31. Rohlmann A, Zander T, Bergmann G: Spinal loads after osteoporotic vertebral fractures treated by vertebroplasty or kyphoplasty. Eur Spine J 15:1255-1264, 2006

32. Rohlmann A, Zander T, Schmidt H, Wilke HJ, Bergmann G: Analysis of the influence of disc degeneration on the mechanical behaviour of a lumbar motion segment using the finite element method. J Biomech 39:2484-2490, 2006

33. Ruberté LM, Natarajan RN, Andersson GBJ: Influence of single-level lumbar degenerative disc disease on the behavior of the adjacent segments-a finite element model study. J Biomech 42:341-348, 2009

34. Schilling C, Krüger S, Grupp TM, Duda GN, Blömer W, Rohlmann A: The effect of design parameters of dynamic pedicle screw systems on kinematics and load bearing: an in vitro study. Eur Spine J 20:297-307, 2011

35. Schmidt H, Heuer F, Claes L, Wilke HJ: The relation between the instantaneous center of rotation and facet joint forcesa finite element analysis. Clin Biomech (Bristol, Avon) 23: 270-278, 2008

36. Schmidt H, Heuer F, Drumm J, Klezl Z, Claes L, Wilke HJ: Application of a calibration method provides more realistic results for a finite element model of a lumbar spinal segment. Clin Biomech (Bristol, Avon) 22:377-384, 2007

37. Schmidt H, Midderhoff S, Adkins K, Wilke HJ: The effect of different design concepts in lumbar total disc arthroplasty on the range of motion, facet joint forces and instantaneous center of rotation of a L4-5 segment. Eur Spine J 18:1695-1705, 2009

38. Schmoelz W, Onder U, Martin A, von Strempel A: Non-fusion instrumentation of the lumbar spine with a hinged pedicle screw rod system: an in vitro experiment. Eur Spine J 18: 1478-1485, 2009

39. Schmoelz W, Schaser KD, Knop C, Blauth M, Disch AC: Extent of corpectomy determines primary stability following isolated anterior reconstruction in a thoracolumbar fracture model. Clin Biomech (Bristol, Avon) 25:16-20, 2010
40. Seligman JV, Gertzbein SD, Tile M, Kapasouri A: Computer analysis of spinal segment motion in degenerative disc disease with and without axial loading. Spine (Phila Pa 1976) 9:566-573, 1984

41. Shirazi-Adl A, Ahmed AM, Shrivastava SC: Mechanical response of a lumbar motion segment in axial torque alone and combined with compression. Spine (Phila Pa 1976) 11:914927, 1986

42. Spitzer V, Ackerman MJ, Scherzinger AL, Whitlock D: The visible human male: a technical report. J Am Med Inform Assoc 3:118-130, 1996

43. White AA, Panjabi MM: Clinical Biomechanics of the Spine, ed 2. Philadelphia: Lippincott, 1990

44. Yong-Hing K, Kirkaldy-Willis WH: The pathophysiology of degenerative disease of the lumbar spine. Orthop Clin North Am 14:491-504, 1983

45. Zander T, Rohlmann A, Bergmann G: Influence of different artificial disc kinematics on spine biomechanics. Clin Biomech (Bristol, Avon) 24:135-142, 2009

46. Zander T, Rohlmann A, Bergmann G: Influence of ligament stiffness on the mechanical behavior of a functional spinal unit. J Biomech 37:1107-1111, 2004

47. Zander T, Rohlmann A, Burra NK, Bergmann G: Effect of a posterior dynamic implant adjacent to a rigid spinal fixator. Clin Biomech (Bristol, Avon) 21:767-774, 2006

48. Zander T, Rohlmann A, Klöckner C, Bergmann G: Influence of graded facetectomy and laminectomy on spinal biomechanics. Eur Spine J 12:427-434, 2003

Manuscript submitted October 1, 2012.

Accepted March 11, 2013.

Please include this information when citing this paper: published online April 19, 2013; DOI: 10.3171/2013.3.SPINE12923. Address correspondence to: Serkan İnceoğlu, Ph.D., Orthopedic Biomechanics Laboratory, Department of Orthopedic Surgery, Loma Linda University, 11406 Loma Linda Drive, Suite 218, Loma Linda, California 92354. email: sinceoglu@llu.edu. 